\title{
Interação entre estudantes cotistas e não cotistas e sua influência na integração social e desempenho acadêmico na universidade
}

Elisa Maria Barbosa de Amorim Ribeiro. Universidade Paulista

Adriano de Lemos Alves Peixoto. Universidade Federal da Bahia

Antonio Virgílio Bittencourt Bastos. Universidade Federal da Bahia

\section{Resumo}

A adoção das cotas nas universidades federais brasileiras instaura a convivência entre grupos de origens sociais distintas, o que repercute em diferentes vivências nos processos de integração social e acadêmica por parte de cotistas e não cotistas. Este estudo utiliza análise de redes sociais para explorar a posição de estudantes de uma universidade federal nas redes sociais informais e suas associações com desempenho acadêmico e comprometimento institucional. Novecentos e vinte e seis estudantes, de cursos de alta e baixa concorrência, responderam um instrumento sobre suas redes e o grau de comprometimento institucional. Os resultados indicam a presença de diferenças importantes entre cotistas e não cotistas nos cursos de alta concorrência: os não cotistas mais populares são os alunos com maior coeficiente de rendimento; o rendimento dos não cotistas esteve mais associado ao estabelecimento de relações intergrupais com não cotistas; e não cotistas com menos relações intergrupais apresentaram menor grau de comprometimento com a universidade. Palavras chave: cotas; análise de redes sociais informais; integração social; integração acadêmica.

\begin{abstract}
Social interaction between affirmative action students and regular students and influences in the social and academic integration at university. The adoption of affirmative action access in Brazilian public universities establishes the coexistence between groups from different social backgrounds with direct repercussion in the way these different groups experience the processes of social and academic integration. This study uses Social Network Analysis to explore how students' position in informal social networks is related with academic performance and institutional commitment. Nine hundred and twenty six students from high and low competition courses took part of a survey about their social informal networks and their institutional commitment. The results indicate important differences between groups in high competition degrees: most popular non affirmative action students are those with higher academic performance; their performance is more associated with in group relations; at the same time, non affirmative action students with fewer intergroup relations have shown lower degree of university commitment.
\end{abstract}

Keywords: affirmative action; social network analysis; social integration; academic integration.

\section{Resumen}

La interacción entre estudiantes ingressos por cupo e no ingressos por cupos y su influencia en la integración social y académica en la universidad. La adopción de cuotas en las universidades públicas brasileñas establece la coexistencia entre grupos de diferentes orígenes sociales que afecta las experiencias en los procesos de integración social y académica de los estudiantes. Este estudio utiliza el análisis de redes sociales para explorar la posición de estudiantes en las redes informales y sus asociaciones con el rendimiento académico y el compromiso institucional. Novecientos y veintiséis estudiantes, de cursos de alta y baja competencia, respondieron a un cuestionario sobre sus redes y el grado de compromiso institucional. Los resultados indican la presencia de diferencias entre estudiantes con ingreso por cupos o non cupos en los cursos altos de competencia. Los estudiantes (non cupo) más populares son los alumnos que presentan coeficiente de rendimiento más alto; los estudiantes (cupo) con más relaciones intergrupales tiene un mejor rendimiento académico; estudiantes (non cupo) con menos relaciones intergrupales tienen un menor grado de compromiso con la universidad. Palabras clave: cupos; análisis de redes sociales informales; integración social; integración académica. 
A transição do ensino médio para a universidade é tradicionalmente considerada um período crítico por demandar do estudante adaptação a este contexto, claramente distinto em relação a processos educativos vivenciados anteriormente. Aspectos como o aumento da complexidade e de ritmo das demandas, impelem aos estudantes transições desenvolvimentais nos domínios acadêmico, social, pessoal e institucional (Tinto, 1994).

Em diversos países as universidades têm passado por mudanças nas regras de seleção e admissão de estudantes, tornando-se um espaço mais acessível para pessoas de baixa renda e/ou pertencentes a grupos minoritários que tradicionalmente não estavam inseridos na universidade. Mas esta passagem para um "ensino de massas" muitas vezes não tem sido acompanhada de mudanças na cultura organizacional universitária, a exemplo de métodos de ensino e currículos construídos e consolidados ao longo do tempo para atender demandas de um público elitizado (Almeida \& Soares, 2004; Ferreira, 2009).

$O$ acesso às universidades federais brasileiras acontece através do sistema cotas, definido com base em critérios sociais e raciais, e do sistema universal, de ampla concorrência. Assim, o público universitário abrange dois grupos heterogêneos quanto à origem escolar, renda e raça: cotistas e não cotistas. Tais diferenças têm repercussões na maneira como cada grupo vai vivenciar o contexto universitário e interagir uns com os outros. Diante da convivência de pessoas de subculturas diversas e das dinâmicas de hierarquização social destas subculturas, o pertencimento a determinados grupos será vantajoso ou desvantajoso a depender da posição destes na rede de interações na universidade (Tinto, 1997, 2006). Nesta direção, Spady (1970) assevera que estudantes com valores e atitudes mais "convencionais" tem maior probabilidade de atrair relações mais próximas com seus pares. Já para os estudantes oriundos de grupos minoritários, a aproximação com grupos tidos ideologicamente como de maior status social tem sido apontada como uma estratégia para lidar com as dificuldades de incluir-se na universidade.

Estudos realizados no Brasil têm demonstrado que o grupo dos cotistas enfrentam mais obstáculos para incluir-se na universidade e manejar demandas de integração social (Ribeiro, 2015; Santos, 2013; Sousa, Bardagi, \& Nunes, 2013) e integração acadêmica (Cunha, 2006; Mendes Junior, 2013; Peixoto et al., 2016). Santos (2013) analisou as diferenças de percepção de vivência acadêmica de estudantes cotistas $(N=1771)$ e não cotistas $(N=3137)$ da Universidade Federal da Bahia.
O estudo comparou o poder preditivo de variáveis de integração social e acadêmica em relação à satisfação com a formação e intenção de evasão dos estudantes. A integração social foi uma variável de distinção entre os dois grupos, sendo mais considerada pelos cotistas como fator de relevância na satisfação com a formação.

Embora os estudantes cotistas valorizem a integração social isso não indica que ela aconteça principalmente na interação com estudantes não cotistas. Como mostram Sousa et al. (2013), cotistas percebem maiores dificuldades em formar vínculos de amizade e possuir rede de apoio. Os autores compararam a autoeficácia na formação superior e as vivências acadêmicas de 204 estudantes por meio de dois instrumentos (AEFS e QVA) ${ }^{1}$. O grupo de cotistas apresentou médias mais baixas em autoeficácia na interação social e na dimensão interpessoal. Já na dimensão institucional, que considera o interesse pela universidade e a intenção de permanecer nela, as médias dos cotistas foram maiores, revelando maior vínculo com a universidade quando comparados aos não cotistas.

Um estudo realizado na Universidade Federal da Bahia (UFBA) por Ribeiro (2015) também demonstra entraves no processo de integração social dos cotistas na universidade. $O$ estudo avaliou o grau de relacionamento entre cotistas e não cotistas em cursos de alta e baixa concorrência. Foram mapeadas as redes sociais informais dos estudantes para avaliar o grau de integração entre cotistas e não cotistas. Os resultados indicaram baixo grau de integração principalmente nos cursos de alta concorrência. Além disso, o grupo de não cotistas apresentou maior tendência a manter relações intragrupo do que os cotistas.

$\mathrm{Na}$ esfera acadêmica, a questão do desempenho dos cotistas está presente desde as primeiras iniciativas de implementação da política de cotas em algumas universidades até os estudos subsequentes de avaliação deste sistema. Sobre as conclusões dos estudos que comparam desempenho de cotistas e não cotistas, os resultados são contraditórios. Encontramos resultados que endossam (Cunha, 2006; Mendes Junior, 2013; Peixoto, Ribeiro, Bastos, \& Ramalho, 2016) ou não identificam diferenças de desempenhos importantes (Guimarães, Costa, \& Almeida Filho, 2011; Queiroz \& Santos, 2010). Em muitas situações o posicionamento ideológico diante das cotas tem direcionado o recorte e a interpretação de dados de pesquisa, muitas vezes utilizados como estratégia argumentativa para dar sustentação ou criticar o sistema de cotas. 
Ainda que a diferença de desempenho seja identificada e que os cotistas apresentem desempenho menor, não se pode de forma simplista atribuir estes efeitos à adesão ao sistema de cotas, ou mesmo à formação básica deficitária desses estudantes. Nos primeiros estudos sobre evasão, havia uma limitada visão de que o estudante era responsável pelo seu fracasso, por não dispor de habilidades, motivação e preparo para vislumbrar os benefícios de concluir uma formação. Após cinco décadas de estudos sobre evasão, sabe-se que o desempenho acadêmico sofre influência de condicionantes individuais e contextuais (Tinto, 1975; Tinto, 2006). Tais condicionantes abrangem aspectos como níveis de articulação entre o ensino e superior secundário; natureza das práticas pedagógicas de ensino aprendizagem; e a posição dos estudantes na rede de interação social (Ferreira, 2009).

As noções de integração acadêmica e social foram desenvolvidas no âmbito dos estudos sobre evasão (Tinto, 1975, 1994, 2006) e têm contribuído para a compreensão do que é relevante para a formação na universidade. Integração acadêmica refere-se à extensão em que os estudantes se adaptam ao cotidiano universitário em termos normativos e estruturais. Um de seus aspectos é o desempenho acadêmico, sendo compreendido como o interjogo entre a habilidade do aluno e os estilos de comportamento desejáveis pela instituição (Tinto, 1975). Já a integração social acontece na extensão em que o estudante mantém relações caracterizadas por processos de comunicação fluidos, suporte social e senso de identidade grupal (Tinto, 1975).

O suporte social obtido da rede de interações representa bem a interdependência entre os sistemas social e acadêmico, pois a rede de suporte viabiliza o acesso ao capital social do grupo entendida como um conjunto de recursos advindos de relações com trocas materiais ou simbólicas (Bourdieu, 1986). Em seus escritos de revisão sobre as pesquisas e modelos explicativos em evasão, Tinto (2006) sugere como agenda de pesquisa o uso de mapeamento de redes de interações para compreender os efeitos da integração social na permanência do estudante. A Análise de Redes Sociais (ARS) tem desenvolvido uma gama de conceitos e medidas que nos permitem avaliar quais os recursos disponíveis na rede, quem consegue acessá-los e de que forma. Boa parte destas informações torna-se palpável a partir da identificação da posição dos atores e dos subgrupos que estes compõem na arquitetura geral da rede.

Os estudos que associam ARS e medidas de desempenho geralmente usam medidas de centralidade como parâmetro para quantificar o capital social dos atores. Tais medidas informam a contribuição de cada ator para a coesão da rede e sua importância está na quantidade de fluxos de comunicação que transitam por ele (Hanneman \& Riddle, 2005). O ator central ocupa uma posição estratégica na rede. Por estar conectado a muitos outros na rede reside em ter alto grau de acessibilidade na rede, por dispor de formas alternativas para satisfazer suas necessidades e aproveitar os recursos da própria rede, o que os torna independente de atores específicos (Freeman, 1979; Hanneman \& Riddle, 2005).

$\mathrm{Na}$ literatura internacional são comuns os estudos que associam as redes de interação entre estudantes com o desempenho acadêmico. Estes estudos têm demonstrado associação positiva entre desempenho e posições de centralidade nas redes sociais, tanto em cursos presenciais (Baldwin, Bedell, \& Johnson, 1997; Hommes et al. 2012; Mayer \& Puller, 2008) como em cursos de educação à distância (EAD) (Akyol, \& Garrison, 2011; Cho, Gay, Davidson, \& Ingraffea, 2007; Gašević, Zouaq, \& Janzen, 2013; Haythornthwaite, Kazmer, Robins, \& Shoemaker, 2000). O estudo de Gašević et al. (2013) identificou as interações entre 505 estudantes na plataforma de um curso de mestrado à distância. As redes foram geradas com base nas informações de acesso a participações em grupos de discussão disponíveis na plataforma virtual. Os pesquisadores encontraram uma associação entre desempenho e centralidade, indicando que quanto menos central é o ator na rede, menor o seu desempenho.

Outro estudo, desenvolvido por Hommes et al (2012), analisou as redes sociais de amizade e informação de 301 alunos de uma disciplina orientada por práticas de aprendizagem colaborativa. $O$ estudo testou um modelo associando desempenho anterior, aprendizagem na disciplina, motivação e integração social às redes informais de interação. O modelo mais ajustado demonstrou uma associação positiva entre centralidade nas redes informais mapeadas com a aprendizagem na disciplina. A partir destes resultados, o estudo conclui sobre a importância de contextos de aprendizagem colaborativa e contato informal entre os estudantes para o desempenho acadêmico.

A relação entre a estrutura da rede e o desempenho acadêmico também sofre influência do padrão das relações intergrupais da rede. Thomas (2000) testou um modelo de integração estudantil, avaliando como características estruturais das redes de estudantes impactavam no desempenho e na permanência na universidade. Uma das estratégias foi analisar o grau de integração entre diferentes subgrupos. Observou-se uma associação 
negativa entre desempenho e padrão de interação mais restrito aos pares dos subgrupos, indicando que poucas relações com o grupo externo reduzem as oportunidades de acessar a estrutura mais geral da rede e seus recursos.

Schofield, Hausmann e Woods (2010) analisaram associações entre padrões de relações intergrupais raciais e desempenho. Eles avaliaram preditores da formação de amizades intergrupais entre universitários negros e brancos, com base em questionários de autorrelato sobre a vida no campus e as interações sociais. Dentre as variáveis estudadas, o desempenho acadêmico foi identificado como um dos preditores de amizade intergrupal. Neste aspecto, estudantes negros com altos escores tenderam a ter mais relações intergrupais quando comparados aos negros com baixo escore.

Além da relação entre desempenho e interação social, a análise de subgrupos na rede e das relações entre eles pode fornecer indicativos importantes dos efeitos da relação com membros de grupos externos no comprometimento com a universidade. A avaliação dos custos e benefícios produzidos pelas interações sociais influencia o comprometimento institucional. Ele refere-se à expectativa pessoal de frequentar uma IES específica e é um importante preditor de permanência. Embora o estudante ao ingressar traga consigo determinado grau de compromisso com sua universidade, este é um dos aspectos de vivência acadêmica mais afetado pela integração social ao longo da formação universitária (Berger \& Braxton, 1998; Thomas, 2000; Tinto, 1975).

No interesse de ampliar a compreensão dos impactos das relações intergrupais entre cotistas e não cotistas na formação acadêmica, o objetivo deste estudo consiste em explorar associações entre a posição dos estudantes cotistas e não cotistas de uma universidade federal pública nas redes sociais informais com desempenho acadêmico e comprometimento institucional.

\section{Método}

Para investigar as relações entre a posição na rede de interações, o desempenho acadêmico e o comprometimento institucional de cotistas e não cotistas foi preciso identificar: as redes sociais de amizade e informação nas turmas; o coeficiente de rendimento; o grau de comprometimento institucional e a forma de ingresso na universidade de cada estudante (sistema universal ou sistema de cotas).

O estudo identificou as relações de amizade e de informação entre estudantes através da aplicação de um questionário em sala de aula. Para realizar este mapeamento foi solicitado a cada um dos participantes que escrevesse os nomes dos colegas da turma que considera seus amigos e os que procura para ter informações sobre as tarefas do curso. Junto às perguntas de mapeamento de rede, o instrumento abrangeu dados sócio demográficos e itens de avaliação do comprometimento institucional. Os itens sobre comprometimento institucional foram extraídos da Escala de Ajustamento ao Ensino Superior (EAJES) elaborada por Magalhães (Santos, 2013). Ao responder o instrumento de pesquisa o estudante informava seu número de matrícula, o que viabilizou o acesso ao coeficiente de rendimento e à forma de ingresso (cotas ou sistema universal) através do setor de tecnologia da universidade. Ao todo, responderam ao questionário 926 alunos dos cursos de: direito e pedagogia, engenharia mecânica e química, medicina e farmácia, letras, design e artes plásticas. Destes, 53\% ingressaram por livre concorrência, $42 \%$ pelo sistema de cotas e $5 \%$ por outras formas de ingresso (como transferências internas, por exemplo).

No intuito de identificar as posições dos alunos na rede e associá-las às variáveis de desempenho e comprometimento institucional, a análise de dados engloba duas etapas. A primeira gera os cálculos das medidas de ARS para cada ator, a saber: centralidade de grau de entrada, eigenvector, excentricidade e E-I index (relações intergrupais). A escolha destas medidas foi orientada pelo resultado dos estudos de Gašević et al. (2013), Hommes et al. (2012), Thomas (2000) e Schofield et al. (2010). Além destas, elegemos a centralidade de eigenvector por considerar a potencialidade das mesmas em elucidar os fenômenos investigados.

A medida de centralidade de grau indica a quantidade vezes que o ator é citado (entrada) e a quantidade de atores que ele cita (saída). A primeira indica o grau de popularidade de um ator na rede e a segunda, o grau de expansividade deste (Hanneman \& Riddle, 2005). A centralidade de eigenvector é sensível para casos em que $\mathrm{o}$ ator tem baixa centralidade, mas está conectado a atores de prestígio na rede (Bonacich, 2007). Já excentricidade de um ator é o caminho mais longo que ele tem que percorrer para alcançar outro nó na rede. Assim, quanto maior a excentricidade, menos central é este ator na rede. O E-I index informa a tendência dos atores, subgrupos e da rede como um todo à homofilia ou heterofilia. A homofilia é considerada um princípio organizativo básico das relações interpessoais e prediz um padrão entre associação e semelhança, no qual o 
contato entre pessoas semelhantes ocorre em uma taxa mais elevada do que entre diferentes - heterofilia (Mcpherson, Smith- Lovin, \& Cook, 2001).

Nesta primeira etapa foram gerados escores normalizados para todas as medidas de redes. Isto se fez necessário em função dos diferentes tamanhos das redes mapeadas (variação do número de alunos por turma tem impacto direto sobre as características estruturais das redes). A segunda etapa da análise de dados consiste em explorar como estas variáveis se associam ao coeficiente de rendimento e ao comprometimento institucional. Tanto para as diferenças entre grupos como para as correlações operacionalizadas, a base de comparação em todas as análises foi por subgrupo estudado - alunos cotistas e não cotistas, e por grau de concorrência dos cursos- alta e baixa.

A medida de comprometimento institucional foi avaliada por meio de uma escala de grau de concordância de cinco pontos. Para realizar os testes de diferenças entre cotistas e não cotistas, identificamos a distribuição dos escores nos quartis e classificamos os participantes em grupos de alto, médio e baixo comprometimento institucional $(\mathrm{Cl})$. A opção pelo uso dos quartis tem relação com a tendência dos participantes do estudo em responder com alto grau de concordância. Como nesta pesquisa foi utilizado um instrumento de auto relato, o efeito da desejabilidade social pode ter interferido na tendência das respostas para alto grau de concordância. Para efeito de comparações entre grupos observamos os estudantes com alto $(\mathrm{Cl}=5)$ e baixo $(\mathrm{Cl} \leq 3,7)$ comprometimento institucional.

A medida de desempenho utilizada, o coeficiente de rendimento (CR), é calculada para todos os alunos do curso a partir das médias nas disciplinas do semestre ponderadas pelos créditos das disciplinas. Os CRs dos estudantes foram transformados em escores padronizados (z). O objetivo da normalização foi equiparar notas de cursos com perfis de avaliação sabidamente lenientes (por exemplo, cursos de humanas) com os CRs dos cursos exigentes (por exemplo, cursos de exatas).

Uma vez levantados os dados de $\mathrm{CR}, \mathrm{Cl}$ e as medidas de redes, estes dados tornaram-se variáveis no banco de dados e passamos ao levantamento das estatísticas descritivas, medidas de comparação de grupos e correlações. Os testes de normalidade indicaram a necessidade de analisar os dados com base em estatísticas não paramétricas. Apenas para os dados de CR foram realizados testes.

Com base nos resultados de Ribeiro (2015) evidenciando a concorrência como uma variável influente no grau de integração entre cotistas e não cotistas, esta variável foi utilizada como critério para a comparação entre estes grupos em todas as análises realizadas. As medidas, comparações de médias e correlações entre as variáveis estudadas foram realizadas para os dois tipos de laços mapeados, amizade e informação.

\section{Resultados}

Antes de apresentar os resultados gerais com as tendências entre as variáveis medidas, são descritas as estatísticas básicas (Tabela 1) de acordo com a forma de acesso (cotista/não cotista), grau de concorrência (alta/ baixa) e tipos de redes (amizade e informação).

Quanto ao coeficiente de rendimento (CR), a média dos estudantes não cotistas é maior do que a dos cotistas, independente da concorrência do curso. Esta diferença entre os grupos é significativa (alta concorrência: $t(531)=-7,07, p<0,001$; baixa concorrência $t(579)=-4,40, p<0,001)$. Como esperado, este resultado apresenta a mesma tendência já observada no estudo de Peixoto et al. (2016), em uma pesquisa realizada com 26.175 estudantes da UFBA. Já quando as diferenças são observadas de acordo com a área de conhecimento, cotistas apresentaram desempenho superior em cursos de artes e de humanidades (média e baixa concorrência).

Quanto à dimensão do vínculo com a universidade, o comprometimento institucional, são identificadas diferenças significativas entre os grupos nos cursos de alta concorrência $(U=17318,500 p<0,001)$. Nestes, os cotistas apresentam maior comprometimento quando comparados aos não cotistas. Um estudo realizado por Sousa et al. (2013) na Universidade Federal de Santa Catarina também identificou maior comprometimento institucional no grupo de cotistas.

Esta diferença de comprometimento pode se dar a partir dos distintos significados de ingressar na universidade para estudantes cotistas e não cotistas. Principalmente para os cotistas de baixa renda, o ensino médio era considerado como a finalização do ciclo de formação escolar. O que se colocava na sequência era o ingresso no mercado de trabalho para complementação da renda familiar. Com o sistema de cotas, mais do que ampliar alternativas de projeto de vida, adquirir a identidade de estudante de uma universidade federal representa inserir-se em categorias profissionais de status social mais valorizado. Já para não cotistas, a universidade sempre esteve nos seus projetos de vida e o ingresso em determinada universidade pública é uma das alternativas possíveis, diante de reais possibilidades de cursar outras universidades, dentro ou fora do país. 
Tabela 1. Estatísticas Descritivas de Coeficiente de Rendimento (CR), Comprometimento Institucional (CI), E-I Index (E-I), Centralidade de Grau De Entrada e Eigenvector Nas Redes de Amizade e Informação e Cursos de Alta e Baixa Concorrência (Conc).

\begin{tabular}{|c|c|c|c|c|c|c|c|c|c|c|c|}
\hline \multirow{2}{*}{ 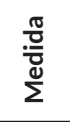 } & \multirow{2}{*}{$\begin{array}{l}\stackrel{0}{\pi ँ} \\
\approx\end{array}$} & \multirow{2}{*}{ Conc } & \multirow{2}{*}{ 을 } & \multirow{2}{*}{$\mathrm{N}$} & \multirow{2}{*}{$M(D P)$} & \multirow{2}{*}{ Mediana } & \multirow{2}{*}{ Min } & \multirow{2}{*}{ Max } & \multicolumn{3}{|c|}{ Percentis } \\
\hline & & & & & & & & & 25 & 50 & 75 \\
\hline \multirow{5}{*}{ ษ } & \multirow{5}{*}{ 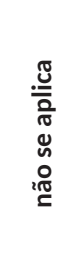 } & \multirow{3}{*}{ Alta } & $C$ & 228 & $-0,33(1,67)$ & $-0,24$ & 0,98 & $-3,84$ & $-0,96$ & $-0,24$ & 0,38 \\
\hline & & & NC & 305 & $0,25(1,78)$ & 0,38 & 0.92 & $-5,73$ & $-0,12$ & 0,38 & 0.91 \\
\hline & & & & & & & & & & & \\
\hline & & \multirow[t]{2}{*}{ Baixa } & c & 277 & $-0,18(2,02)$ & $-0,07$ & 0,94 & $-3,48$ & $-0,80$ & $-0,07$ & 0,49 \\
\hline & & & NC & 306 & $0,16(2,56)$ & 0,34 & 0,99 & $-4,08$ & $-0,36$ & 0,34 & 0,85 \\
\hline \multirow{2}{*}{$\bar{\Xi}$} & \multirow{2}{*}{ ֻٌ } & \multirow{2}{*}{ Alta } & $C$ & 168 & $4,33(5)$ & 4,59 & 0,71 & 1,67 & 4 & 4,59 & 5,00 \\
\hline & & & NC & 251 & $4,08(5)$ & 4,33 & 0,8 & 1 & 3,67 & 4,33 & 4,67 \\
\hline \multirow{4}{*}{$\bar{\Psi}$} & \multirow{2}{*}{$\bar{\Sigma}_{\alpha}$} & \multirow{2}{*}{ Alta } & c & 217 & $-0,13$ & $-0,14$ & 0,62 & -1 & $-0,6$ & $-0,14$ & 0,25 \\
\hline & & & NC & 295 & $-0,35(1)$ & $-0,43$ & 0,58 & -1 & $-0,85$ & $-0,43$ & 0 \\
\hline & \multirow[b]{2}{*}{$\underline{\underline{\underline{z}}}$} & \multirow[b]{2}{*}{ Alta } & $c$ & 191 & $-0,18(1)$ & $-0,14$ & 0,68 & -1 & -1 & $-0,14$ & 0,33 \\
\hline & & & NC & 264 & $-0,4(1)$ & $-0,5$ & 0,59 & -1 & -1 & $-0,5$ & 0 \\
\hline \multirow{2}{*}{ 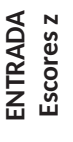 } & \multirow{2}{*}{$\begin{array}{l}\frac{u}{\vec{N}} \\
\frac{N}{<}\end{array}$} & \multirow{2}{*}{ Alta } & c & 214 & $-0,13(3,44)$ & $-0,30$ & 0,95 & $-1,58$ & $-0,84$ & $-0,30$ & 0,40 \\
\hline & & & NC & 291 & $0,10(4,07)$ & 0,01 & 1,01 & $-1,96$ & $-0,67$ & 0,01 & 0,69 \\
\hline \multirow{11}{*}{ 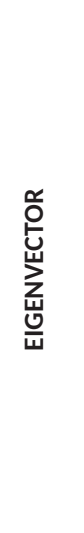 } & \multirow{6}{*}{$\bar{\sum}$} & \multirow{4}{*}{ Alta } & $c$ & 214 & $0,20(1)$ & 0,08 & 0,26 & 0,00 & 0,02 & 0,08 & 0,31 \\
\hline & & & & & & & & & & & \\
\hline & & & NC & 291 & $0,29(1)$ & 0,13 & 0,32 & 0,00 & 0,04 & 0,13 & 0,55 \\
\hline & & & C & 258 & $0,27(1)$ & 0,18 & 0,27 & 0,00 & 0,03 & 0,18 & 0,41 \\
\hline & & Baixa & & & & & & & & & \\
\hline & & & NC & 295 & $0,31(1)$ & 0,22 & 0,29 & 0,00 & 0,06 & 0,22 & 0,48 \\
\hline & \multirow{5}{*}{$\underline{\underline{u}}$} & & $C$ & 191 & $0,16(1)$ & 0,05 & 0,23 & 0,00 & 0,00 & 0,05 & 0,23 \\
\hline & & Alld & NC & 264 & $0,23(1)$ & 0,10 & 0,28 & 0,00 & 0,01 & 0,10 & 0,34 \\
\hline & & & $c$ & 254 & $0,20(1)$ & 0,07 & 0,27 & 0,00 & 0,00 & 0,07 & 0,33 \\
\hline & & Baixa & & & & & & & & & \\
\hline & & & NC & 275 & $0,27(1)$ & 0,14 & 0,30 & 0,00 & 0,02 & 0,14 & 0,46 \\
\hline
\end{tabular}

As associações realizadas neste estudo entre a medida de comprometimento institucional dos alunos e as posições assumidas na rede de interações auxiliam no levantamento de hipóteses para a compreensão deste fenômeno, discussão que será retomada durante esta seção de resultados. Dando continuidade à descrição das variáveis estudadas, são comparadas as medidas das posições na rede assumidas pelos estudantes cotistas e não cotistas (Tabela 1).

Para avaliar a tendência de cada aluno se relacionar com pares ou com membros do grupo externo foi utilizada a medida de E-I index. Quando comparados, os grupos de cotistas e não cotistas apresentam diferenças importantes nos cursos de alta concorrência tanto na rede de amizade $(U=25143 ; p<0,001)$ como na de informação $(U=20643 ; p<0,001)$. Embora ambos os grupos tenham tendência à homofilia, os não cotistas apresentam índices significativamente maiores.

Dentre as medidas de centralidade utilizadas, há diferença na centralidade de grau de entrada de amizade para cotistas e não cotistas nos cursos de alta concorrência $(U=26971, p<0,01)$. Os não cotistas têm maior centralidade de grau de entrada, ou seja, são mais citados pelos colegas da turma que os cotistas. 
Na medida de centralidade de eigenvector, que considera centrais atores conectados a outros atores prestígio na rede, os não cotistas têm maior centralidade, não importa a concorrência do curso ou a natureza do laço. Ainda assim, a concorrência alta na rede de amizade apresenta a maior significância $(U=25952,50 p<$ $0,001)$ quando comparada às demais, a saber: rede de amizade baixa concorrência $(U=34333,50 p<0,05)$ e rede de informação para grupos de alta $(U=21424,500$ $p<0,01)$ e baixa concorrência $(U=30209,500 p<0,01)$.

Este padrão de interação expresso nas medidas de centralidade e de E-I index repercutem no controle de acesso a informações e recursos presentes na rede de interação social na universidade. No intuito de avançar na compreensão dos impactos deste padrão de interação para cotistas e não cotistas são avaliadas as associações destas medidas com desempenho acadêmico e comprometimento institucional.

\section{Desempenho (CR) e Posição dos Estudantes na Rede de Interações}

Dentre as posições na rede analisadas e associadas com desempenho, foram encontradas correlações significativas para as medidas de centralidade de grau de entrada e homofilia (E-I index), para ambos os laços pesquisados (amizade e informação) (Tabela 2).

Tabela 2. Correlações entre Coeficiente de Rendimento (CR) e Posições nas Redes de Amizade e Informação, para Cotistas e Não Cotistas em Cursos de Alta e Baixa Concorrência.

\begin{tabular}{cccccc}
\hline Grupo & Concorrência & $\begin{array}{c}\text { Grau de Entrada } \\
\text { Amizade }\end{array}$ & $\begin{array}{c}\text { Grau de Entrada } \\
\text { Informação }\end{array}$ & $\begin{array}{c}\text { E-I } \\
\text { Amizade }\end{array}$ & $\begin{array}{c}\text { E-I } \\
\text { Informação }\end{array}$ \\
\hline \multirow{2}{*}{ Cotista } & Alta & $0,40^{* *}$ & $0,37^{* *}$ & $0,21^{* *}$ & $0,31^{* *}$ \\
& Baixa & $0,29^{* *}$ & $0,34^{* *}$ & $-0,07$ & 0,00 \\
\multirow{2}{*}{ Não cotista } & Alta & $0,37^{* *}$ & $0,41^{* *}$ & $0,14^{*}$ & $-19^{* *}$ \\
& Baixa & $0,42^{* *}$ & $0,47^{* *}$ & $-0,07$ & $-16^{* *}$ \\
\hline
\end{tabular}

\footnotetext{
${ }^{* *} p<0,001 ;{ }^{*} p<0,01$
}

Os alunos mais populares nas turmas são os que apresentam melhor rendimento acadêmico, não importa o nível de concorrência ou a natureza do laço (Tabela 2). Esta correlação positiva entre centralidade de grau de entrada e desempenho (CR) é mais intensa para estudantes cotistas de cursos de alta concorrência na rede de amizade $\left(r_{s}=0,40\right)$, e para não cotistas em cursos de baixa concorrência em ambos os tipos de laço $\left(r_{s}=0,42\right.$, amizade; $r_{s}=0,47$, informação). Além das variações encontradas por tipo de laço e de acordo com o grupo em questão (cotistas ou não cotistas), outras variáveis podem exercer influência nesta associação, a exemplo de variáveis de natureza idiossincrática.

A constatação da associação entre desempenho e popularidade gera perguntas sobre a direção desta associação, se desempenho atrai contatos e/ ou se amigos favorecem o desempenho. Em seus escritos, Tinto $(1975,1997)$ considera um dos aspectos que influenciam esta direção, aos destacar que laços de amizade favorecem o desempenho quando são estabelecidos com estudantes com forte orientação acadêmica. A formação de laços desta natureza provê uma rede de suporte social que motiva e auxilia nas tarefas da universidade (Tinto, 1975; Tinto 1997).

O comportamento da correlação da centralidade de grau com desempenho apresenta a mesma tendência nas redes de informação: quanto maior o desempenho do estudante maior a sua centralidade de grau. Estas correlações positivas na rede de informação são mais expressivas quando comparadas às da rede de amizade, exceto para cotistas de alta concorrência (02). No caso dos laços estabelecidos na rede de informação, é provável que o prestígio na rede seja consequente do desempenho. Neste caso em que a busca por contato tem o intuito de acessar informações, os estudantes com melhor desempenho são considerados fontes legítimas por dominarem o repertório comportamental esperado pela universidade.

Quando são avaliadas associações entre a tendência em manter ou evitar relações intergrupais (E-I index) e desempenho (CR), encontram-se correlações positivas para cotistas e negativas ou inexistentes para não cotistas. Ao comparar o grupo de cotistas (Tabela 2) em função da concorrência, observamos correlações positivas mais expressivas para os cotistas de cursos de alta concorrência, principalmente na rede de informação $\left(r_{s}=0,31\right)$. Isso significa dizer que para estes estudantes, estabelecer relações com os não cotistas está associado com melhor desempenho. Em um estudo realizado por Schofield et al. (2010) estudantes negros com altos escores também mantiveram mais relações intergrupais. Os autores sugerem que estes estudantes 
podem se sentir mais à vontade para estabelecer contato com colegas brancos.

Além de centrar-se sobre aspectos idiossincráticos, a direção causal desta hipótese proposta por Schofield et al. (2010) é de que desempenho antecede relação intergrupal. No entanto, quando refletimos sobre redes de interação entre alunos como recurso de suporte para aprendizagem (Tinto, 2006), pode-se construir a hipótese de que a interação com não cotistas tende a favorecer a assunção de habilidades necessárias ao bom desempenho. Ao analisar a percepção de vivência acadêmica de estudantes cotistas da UFBA, Santos (2013) aponta o fator interação social como mais relevante para a satisfação dos cotistas com a formação, quando comparados aos não cotistas. Assim, a formação de uma rede com a presença de laços intergrupais (cotistas vinculados a não cotistas) pode representar o acesso aos trâmites e à lógica do funcionamento acadêmico e, consequentemente, melhores resultados acadêmicos, aos quais estudantes provenientes de escolas particulares (não cotistas em sua maioria) estão mais habituados do que estudantes de escolas públicas.

Até aqui demonstramos associações entre a posição do aluno na rede de interações e seu desempenho. Outro importante aspecto indicado pelos estudos de evasão que sofre influência da integração social na universidade é o comprometimento institucional. Embora no ingresso da faculdade seu índice tenha relação com expectativas anteriores relativas à instituição, ele se modifica ao longo da formação e estas alterações acontecem muito em função do grau de integração social do estudante (Berger \& Braxton, 1998; Tinto, 1975).

Uma vez apresentadas as associações entre posição na rede e desempenho, demonstramos os índices de posição na rede que apresentaram diferenças importantes nos grupos de alto e baixo comprometimento institucional.

\section{Comprometimento Institucional (Cl) e Posição na Rede}

Nesta seção são comparados os grupos de alto e baixo comprometimento (definidos a partir dos quartis) quanto aos índices de E-I index e centralidade. Estão relatadas as medidas em que foram encontradas diferenças significativas entre os grupos de alto e baixo comprometimento, são elas: E-I index e excentricidade para não cotistas (Tabela 3).

Tabela 3. Estatísticas Descritivas de E-I Index para não Cotistas de Alto e Baixo Comprometimento Institucional

\begin{tabular}{|c|c|c|c|c|c|c|c|c|c|}
\hline \multirow{2}{*}{ Medida } & \multirow{2}{*}{ Rede } & \multirow{2}{*}{$\mathrm{Cl}$} & \multirow{2}{*}{$M(D P)$} & \multirow{2}{*}{ Mediana } & \multirow{2}{*}{ Mín } & \multirow{2}{*}{ Máx } & \multicolumn{3}{|c|}{ Percentis } \\
\hline & & & & & & & 25 & 50 & 75 \\
\hline \multirow{2}{*}{ 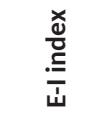 } & \multirow{2}{*}{$\begin{array}{l}\frac{0}{0} \\
\frac{N}{E} \\
\frac{\pi}{<}\end{array}$} & Alto & $-0,25(-1)$ & $-0,33$ & -1 & 1 & $-0,75$ & $-0,33$ & 0,14 \\
\hline & & Baixo & $-0,45(-1)$ & $-0,55$ & -1 & 1 & -1 & $-0,55$ & 0 \\
\hline \multirow{4}{*}{ 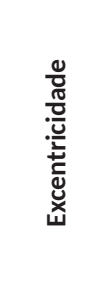 } & \multirow{2}{*}{$\frac{\mathbb{0}}{\frac{N}{N}}$} & Alto & $7,16(5)$ & 7,00 & 0,00 & 18,00 & 4,25 & 7,00 & 10,00 \\
\hline & & Baixo & $5,81(6)$ & 6,00 & 0,00 & 16,00 & 3,00 & 6,00 & 10,00 \\
\hline & \multirow{2}{*}{ 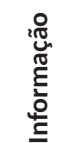 } & Alto & $5,71(9)$ & 6,00 & 0,00 & 18,00 & 3,00 & 6,00 & 9,00 \\
\hline & & Baixo & $4,15(0)$ & 4 & 0 & 14 & 2 & 4 & 6 \\
\hline
\end{tabular}

Estudantes não cotistas com alto e baixo comprometimento institucional em cursos de alta concorrência apresentam diferenças significativas na tendência à homofilia $(U=3030,0, p<0,01)$. Os estudantes não cotistas menos comprometidos com a instituição estabelecem poucas relações com cotistas na rede de amizade.

A excentricidade informa a maior distância existente entre dois nós. Quando um ator tem excentricidade elevada indica que ele é menos central na rede. Identificamos diferenças entre alunos com alto e baixo comprometimento nesta medida (rede de amizade: $U=3067,5$, rede de informação: $p<0,02, U=2821, p<0,01)$. Os alunos não cotistas com maior comprometimento institucional são menos centrais nos cursos de alta concorrência.

As associações entre comprometimento e posições na rede são intrigantes, pois não encontramos a imbricação apontada na literatura entre comprometimento institucional e integração social. Por um lado, os não cotistas mais centrais na rede têm maior homofilia e menor 
comprometimento. Uma vez que a política de cotas integra as ações da universidade e os não cotistas muitas vezes a consideram injusta, será que isto estaria afetando o vínculo com a universidade? No grupo dos estudantes com alto comprometimento encontramos tanto os estudantes cotistas como os não cotistas que ocupam posições menos centrais. Seria o debate silencioso pró e contra cotas expressando-se na estrutura geral da rede?

\section{Conclusões}

Este estudo se diferencia em apresentar um escopo mais amplo de análise de posições na rede e influências na vivência e desempenho acadêmico. Primeiro ao inserir cursos de graduação pertencentes a todas as áreas de conhecimento e de alta e baixa concorrência no ENEM. Depois por avaliar a relação entre relações intergrupais (homofilia) com desempenho e comprometimento institucional, quando a maioria dos estudos centra na análise de medidas de centralidade. Por fim, é o segundo estudo no Brasil que utiliza análise de redes sociais de redes reais (não virtuais) como medida de avaliação de integração social na universidade, pois até então esta tem sido medida através de questionários de vivência acadêmica (Almeida, Soares, \& Ferreira, 2002) que utilizam itens de autorrelato.

Dando sequência ao estudo de Ribeiro et al. (2014) que analisa as redes e as relações intergrupais entre cotistas e não cotistas na universidade, utilizamos o mapeamento das redes para ampliar a base de dados com as medidas de centralidade, desempenho e comprometimento institucional, associando-as às medidas de homofilia. A avaliação da homofilia no estudo de Ribeiro et al. (2014) foi realizada no nível da rede e do grupo de cotistas e não cotistas. No presente estudo esta medida é considerada para cada estudante e permitiu avaliar a tendência de cada um relacionar-se com membros do próprio grupo ou do grupo externo.

A partir deste conjunto de dados e dos recortes por concorrência e tipo de laço, foi possível pensar na associação entre dados de rede e desempenho e comprometimento. A posição dos estudantes na rede esteve associada tanto a desempenho como ao comprometimento institucional. As medidas de centralidade e excentricidade permitiram aprofundar a visão da posição dos cotistas e não cotistas na estrutura da rede como um todo. Este conjunto de dados nos fez perceber além da questão da baixa integração entre os estudantes cotistas e não cotistas em cursos de alta concorrência. Os subgrupos poderiam estar desagregados, mas, ainda assim, apresentarem perfis de centralidade próximos na estrutura da rede como um todo. Mas os dois grupos apresentam tendências opostas, com não cotistas mais no centro das redes e cotistas na periferia delas (nos cursos de alta concorrência), expressando a manutenção de uma hierarquia social que o sistema de cotas deve suplantar.

A necessidade de identificar os participantes do estudo, tanto para detectar a forma de ingresso (cotas ou sistema universal) ou para ter acesso ao coeficiente de rendimento, influenciou na decisão de circunscrever as redes às turmas. Foi preciso limitar as possibilidades de citação aos alunos daquela turma. Assim, nossa medida compõe a noção de integração social na universidade, mas integração social é mais ampla que a medida utilizada. Nesta direção, é importante realizar estudos que abranjam a interação com estudantes de outros semestres (Thomas, 2000) e cursos, professores e funcionários.

O vínculo com a universidade, expresso na medida de comprometimento institucional foi avaliado por itens da escala de ajustamento ao ensino superior. Como toda medida baseada em autorrelato ela esteve sujeita à desejabilidade social. Além disso, a medida via escala likert apresenta uma tendência em direção a uma concentração no centro da escala. Dada a importância desta medida como preditora de evasão e da sua forte associação com integração social, é preciso aprofundar parâmetros de avaliação deste vínculo através de estratégias qualitativas.

Existem estudos que avaliam o impacto da renda na consecução de suporte social. Lee, Ruan e Lai (2005) compararam redes de suporte social em Pequim e Hong Kong e observaram que em Hong Kong a renda tem papel relevante para obtenção de suporte social. No Brasil, Soares (2008) considerou a influência da pobreza no acesso ao suporte social em redes egocentradas em São Paulo (Brasil). Diante destes resultados, torna-se importante realizar estudos futuros para avaliar associações entre a renda dos estudantes e a posição que assumem nas redes sociais informais.

Outra questão a ser considerada é a diversidade dos membros do grupo de cotistas e de não cotistas. O primeiro é formado por estudantes negros, indígenas e pardos que realizaram o ensino médio em escolas públicas. Além disso, metade destes estudantes deve ter renda familiar inferior ou igual a um salário mínimo e meio per capita. Os não cotistas também apresentam diferenças na renda, cidade e bairro de origem escolar (escolas públicas de alta qualidade ou particulares de baixa qualidade, por exemplo). Diante destas diferenças é preciso realizar estudos delineados para correlacionar 
desempenho acadêmico e integração social e acadêmica, a partir dos diferentes extratos que configuram ambos os grupos.

Ainda sobre estudos futuros, Tinto $(1975,1997$, 2006) sugere associar estudos de mapeamento de redes com dados de evasão. Seria interessante observarmos a trajetória dos participantes deste estudo quanto à permanência, tempo de conclusão do curso e evasão, associando estes dados com a posição destes estudantes na rede. Além da identificação do dado de evasão ou permanência, mapeamentos subsequentes das redes dos alunos em um desenho de pesquisa longitudinal e a análise comparativa da dinâmica das configurações das redes ampliará a compreensão dos processos de interação entre os estudantes cotistas e não cotistas.

Associar este estudo com um estudo qualitativo nos permitirá acessar mecanismos processuais, percepções e trajetórias tanto grupais como individuais. É preciso oferecer espaço de escuta aos alunos e avaliar a percepção deles sobre a convivência entre cotistas e não cotistas. Considerar se estes percebem um distanciamento entre os grupos, a que atribuem este distanciamento e o que pensam como estratégias de integração.

\section{Referências}

Akyol, Z., \& Garrison, D. R. (2011). Understanding cognitive presence in an online and blended community of inquiry: assessing outcomes and processes for deep approaches to learning. British Journal of Educational Technology, 42(2), 233-250. doi: 10.1111/j.1467-8535.2009.01029.x

Almeida, L. S., \& Soares, A. P. (2004). Os estudantes universitários: sucesso escolar e desenvolvimento psicossocial. In E. Mercury \& S. A. J. Polydoro (Orgs.), Estudante universitário: características e experiências de formação (pp.15-40). Taubaté: Cabral Editora.

Almeida, L. S., Soares, A. P. C., \& Ferreira, J. A. (2002). Questionário de Vivências Académicas (QVA-r): Avaliação do ajustamento dos estudantes universitários. Avaliação Psicológica, 2, 81-93. Recuperado de http://repositorium.sdum.uminho.pt/bitstream/1822/12074/1/ Almeida\%2c\%20Soares\%20\%26\%20Ferreira\%2c\%202002.pdf

Baldwin, T. T., Bedell, M. D., \& Johnson, J. L. (1997). The social fabric of a team-based MBA program: network effects on student satisfaction and performance. Academy of Management Journal, 40(6), 13691397. doi: $10.2307 / 257037$

Berger, J. B., \& Braxton, J. M. (1998). Revising Tinto's interactionalist theory of student departure through theory elaboration: examining the role of organizational attributes in the persistence process. Research in Higher Education, 39(2), 103-119. doi: 10.1023/A:101876051

Bonacich, P. (2007). Some unique properties of eigenvector centrality. Social Networks, 29(4), 555-564. doi:10.1016/j.socnet.2007.04.002
Bourdieu, P. (1986). The forms of capital. In I. Szeman \& T. Kaposy (Orgs.), Cultural theory: an anthology (pp. 81-93). Madden, MA: Wiley-Blackwell.

Cho, H., Gay, G., Davidson, B., \& Ingraffea, A. (2007). Social networks, communication styles, and learning performance in a CSCL community. Computers \& Education, 49(2), 309-329. doi: 10.1016/j. compedu.2005.07.003

Cunha, E. M. P. (2006). Sistema universal e sistema de cotas para negros na Universidade de Brasília: um estudo de desempenho (Dissertação de Mestrado). Recuperado de http://repositorio.unb. br/handle/10482/2365

Ferreira, M. (2009). Determinantes do rendimento académico no ensino superior. Revista Internacional Dhumanitats, 15, 55-60. Recuperado de http://www.hottopos.com/rih15/marcof.pdf

Freeman, L. C. (1979). Centrality in social networks conceptual clarification. Social Networks, 1(3), 215-239. doi: 10.1016/0378-8733(78)90021-7

Gašević, D., Zouaq, A., \& Janzen, R. (2013). "Choose your classmates, your GPA is at stake!": the association of cross-class social ties and academic performance. American Behavioral Scientist, 57(10), 1460-1479. doi: 10.1177/0002764213479362

Guimarães, A. S., Costa, L., \& Almeida Filho, N. (2011). Inclusão social nas universidades brasileiras: o caso da UFBA. In D. C. Fernandes \& D. H. Hegal (Orgs.), As cores da desigualdade (1를. ed., pp. 19-41). Belo Horizonte : Fino Traço.

Hanneman, R. A., \& Riddle, M. (2005). Introduction to social network methods. Riverside, CA: University of California.

Haythornthwaite, C., Kazmer, M. M., Robins, J., \& Shoemaker, S. (2000). Community development among distance learners: temporal and technological dimensions. Journal of Computer Mediated Communication, 6(1), 0-0. doi:10.1111/j.1083-6101.2000.tb00114.x

Hommes, J, Rienties, B., De Grave, W., Bos, G., Schuwirth, L., \& Scherpbier, A. (2012). Visualising the invisible: a network approach to reveal the informal social side of student learning. Advances in Health Sciences Education, 17(5), 743-757. doi: 10.1007/s10459-012-9349-0

Lee, R. P., Ruan, D., \& Lai, G. (2005). Social structure and support networks in Beijing and Hong Kong. Social Networks, 27(3), 249-274. doi: 10.1016/j.socnet.2005.04.001

Mayer, A., \& Puller, S. L. (2008). The old boy (and girl) network: social network formation on university campuses. Journal of Public Economics, 92(1), 329-347. doi: 10.1016/j.jpubeco.2007.09.001

McPherson, M., Smith-Lovin, L., \& Cook, J. M. (2001). Birds of a feather: homophily in social networks. Annual Review of Sociology, 27, 415444. doi: 10.1146/annurev.soc.27.1.415

Mendes Junior, A. A. F. (2013). Três ensaios sobre ações afirmativas no ensino superior brasileiro: Acesso, progressão e simulações de diferentes políticas de cotas para a Universidade do Estado do Rio de Janeiro (Dissertação de mestrado). Recuperado de http://www. proac.uff.br/cede/sites/default/files/Monografia-Alvaro_Mendes.pdf

Peixoto, A. L. A., Ribeiro, E. M. B. A., Bastos, A. V. B., \& Ramalho, M. C. (2016). Cotas e desempenho acadêmico na UFBA: um estudo a partir dos coeficientes de rendimento. Revista de Avaliação da Educação Superior. 21(2), 569-591. doi: 10.1590/ S1414-40772016000200013

Queiroz, D. M.; \& Santos, J.T. (2010). Ações afirmativas para negros no ensino superior e desempenho de estudantes. In L. F. Costa \& M. L. Messeder (Orgs.), Educação, multiculturalismo e diversidade (pp. 87-99). Salvador: EDUFBA. 
Ribeiro, E. M. B. A.(2015). Análise de redes sociais e relações intergrupais: a convivência entre cotistas e não cotistas e suas influências na formação acadêmica (Tese de Doutorado). Recuperado de http://www.pospsi.ufba.br/Elisa_Ribeiro.pdf

Ribeiro, E. M. B. A., Bastos, A. V. B., Peixoto, A. L. A., Miranda, J. G. V., Cruz, F.V., Amaral. L. L. L., ... Souza, V. A. S. (2014). Análise de redes sociais e processos de integração grupal: avaliando os impactos da política afirmativa de cotas em uma universidade pública. Relatório de Pesquisa/2014. Salvador: PROUFBA. Recuperado de https:// repositorio.ufba.br/ri/handle/ri/15630

Santos, P.V.S. (2013). Adaptação à universidade dos estudantes cotistas e não cotistas: relação entre vivência acadêmica e intenção de evasão (Dissertação de mestrado). Recuperado de http://www. repositorio.ufba.br:8080/ri/handle/ri/14513

Schofield, J. W., Hausmann, L. R. M., YE, F., \& Woods, R. L. (2010). Intergoup friendship on campus: predicting close and casual friendiships between White and African American first-year college students. Group Processes \& Intergroup Relations, 13(5), 585-602. doi: $10.1177 / 1368430210362437$

Soares, R. B. (2008). Pobreza, segregação e redes sociais: um estudo sobre o impacto da remoção dos moradores da favela Guinle, Guarulhos/SP (Dissertação de mestrado). doi: 10.11606/D.8.2009. tde-03112009-162339
Sousa, H., Bardagi, M. P., \& Nunes, C. H. S. S. (2013). Autoeficácia na formação superior e vivências de universitários cotistas e não cotistas. Avaliação Psicológica, 12(2), 253-261. Recuperado de http://pepsic.bvsalud.org/scielo.php?script=sci_arttext\&pi$\mathrm{d}=$ S1677-04712013000200016\&lng=pt\&tlng=pt

Spady, W. G. (1970). Dropouts from higher education: an interdisciplinary review and synthesis. Interchange, 1(1), 64-85. doi: 10.1007/ BF02214313

Thomas, S. L. (2000). Ties that bind: a social network approach to understanding student integration and persistence. Journal of Higher Education, 75(5) 591-615. doi: 10.1080/00221546.2000.11778854

Tinto, V. (1975). Dropout from higher education: a theoretical synthesis of recent research. Review of Educational Research, 45(1), 89-125. doi: $10.2307 / 1170024$

Tinto, V. (1994). Building learning communities for new college students: a summary of research findings of the Collaborative Learning Project. University Park, PA: Pennsylvania State University NCTLA.

Tinto, V. (1997). Classrooms as communities: exploring the educational character of student persistence. Journal of Higher Education, 68(6) 599-624. doi: 10.2307/2959965

Tinto, V. (2006). Research and practice of student retention: what next? Journal of College Student Retention: Research, Theory \& Practice, 8(1), 1-19. doi: 10.2190/4YNU-4TMB-22DJ-AN4W

1. Escala de Autoeficácia na Formação Superior (AEFS) e Questionário de Vivências Acadêmicas (QVA). Ambos os instrumentos avaliam aspectos formais (carreira, planejamento, metas, etc.), subjetivos (autoconceito, proatividade, etc.) e interacionais (relacionamento).

Elisa Maria Barbosa de Amorim Ribeiro, Doutorado em Psicologia Social e do Trabalho na Universidade Federal da Bahia (UFBA), é Professora Titular da Universidade Paulista (UNIP) de São José dos Campos e Professora Doutora da Universidade do Vale do Paraíba (UNIVAP) em São José dos Campos. Endereço para correspondência: Rua Vicente de Finis, 170, Residencial Eldorado, Urbanova. São José dos Campos/SP. CEP 12244320. Telefone:1233220522. E-mail: ribeiro.emba@gmail.com

Adriano de Lemos Alves Peixoto, Doutor em Psicologia pela Universidade de Sheffield, é Professor Adjunto do Instituto de Psicologia da Universidade Federal da Bahia (UFBA).

E-mail: adriano.apeixoto@gmail.com

Antonio Virgilio Bittencourt Bastos, Doutor em Psicologia pela Universidade de Brasília (UNB) na área de Psicologia Organizacional e do Trabalho, é Professor Titular do Instituto de Psicologia da Universidade Federal da Bahia (UFBA). E-mail: virgilio@ufba.br 